\title{
Experiencing the progress report: an analysis of gender in doctoral candidature.
}

Authors: Inger Mewburn (ANU), Ekaterina Tokareva (RMIT) and Denise Cuthbert (RMIT)

\begin{abstract}
Most universities around the world put in place administrative processes and systems to manage research student progress. These processes usually involve filling out standardised forms and instruments; managerial tools intended to increase transparency, promote efficiency and ensure fairness by applying the same standards to all. One of the most widely used management tools in doctoral candidature within Australia, and in other countries which look to the UK for degree structure and format, is the progress report (Mewburn, Tokareva, Barnacle, Sinclair \& Cuthbert, 2013). This reporting mechanism requires students and supervisors to make a retrospective account of the research done in a given period. The intention of the progress report is to provide a mechanism for recording feedback and an opportunity to clarify communication between supervisors, students and the institution itself on the progress of the research. However whether these managerial tools achieve these aims in doctoral candidature is questionable. In this paper we report on findings from a study of progress reporting in doctoral studies in one middle band university in Australia. We found men and women reported qualitative differences in their encounters with the progress reporting mechanisms, which called into question the idea that these management tools are gender neutral and fair in their effects or application.
\end{abstract}

\section{Keywords}

doctoral study, research, gender, university management, feedback, administrative processes

\section{Corresponding Author}

Dr Inger Mewburn 
Director of research training

Australian National University

\section{Introduction}

This paper offers an analysis of a little studied area of doctoral education: students' negotiation of the administrative requirement to report on progress. Progress reports have become a common tool for managing research candidature in Australia and elsewhere in the world (Mewburn, Tokareva, Barnacle, Sinclair \& Cuthbert, 2013). Practices vary from institution to institution, but most universities ask research students and their supervisors to make a periodic report in writing on progress towards completion of the degree. While thehe exact composition of the reporting forms vary, the progress report will include an account of the research done, what is planned and the opportunity to request extra resources, report problems and assess overall student (and sometimes supervisor) performance. Progress reports are high stakes documents which may be used by the institution in a number of ways to directly affect student outcomes, for example as evidence in grievance processes and in applications for extensions of time.

Although the progress report may be understood as an expression of 'managerialist' impulses, and the consequent development of a pervasive audit culture within academia (Strathern, 2000), its effectiveness as an instrument of surveillance and control is questionable. In a previous paper published from this study (Mewburn, Tokoreva, Barnacle, Sinclair \& Cuthbert, 2012) we showed that progress reporting is a site of considerable resistance and tension. Put simply, not all progress reports are accurate or truthful reflections of academic progress in the degree. This research showed that research candidates engaged in complex negotiations with the university as a workplace through the progress reporting process. Our initial examination of the data indicated that women and men experienced the progress reporting system differently, accordingly we returned to the data and undertook a comparison of the language the students of each gender 
used to describe their experiences and the differences between stories of conflict. This paper offers an analysis of students' negotiation of administrative systems from the point of view of gender. It draws on interviews conducted with twenty research candidates in different disciplines about their understandings and practices in reporting on their progress.

Through this analysis we found evidence of gendered practices around progress reporting which appear to transcend disciplinary boundaries, particularly in relation to social interactions and academic working relationships. We sketch out the extensive literature on doctoral study and gender and draw on other literature of gendered practices in the academy. We then present our analysis of the interview data, arguing that gender is a key variable in the working relationships between students and supervisors, and their interactions with the administrative structures of the university, but not in a simple way. Women and men experience the progress report differently in three key ways: as a process of subjectification, as a way to solve problems and as a key part of negotiating their relationship with their supervisor. Some inconsistencies we observed in this data only reinforced our argument that management tools like the progress report are not, by nature, instruments which necessarily produce fair and equitable outcomes. Given the large numbers of students who fail to complete their research degrees -- around one third according to latest data from Australia (Edwards et al, 2009) and up to 40 per cent in the USA (Golde, 2005) -- factors inhibiting success are important for both institutions and individuals and a better understanding of all the factors which affect progress in particular is crucial. We conclude with some suggestions for supervisors and administrators who have responsibility for this aspect of doctoral candidature.

\section{Gender in the academy and research degree study}

Many studies explore the different experiences female and male students have in graduate schools. Despite implementation of gender equity policies, grievance procedures and other 
gender neutral measures in Europe, the USA and other anglophone countries, women still face obstacles on their way to the doctorate and beyond in their academic careers (Erickson, 2012, Dever, 2008). A recurring focus is the lack (or lack of visibility) of female role models in research and in the academy generally (Erickson, 2012, Alpay, Hari, Kambouri \& Ahearn, 2010, Ferreira, 2003). Research from Europe, North America, Australia and New Zealand shows that, although the numbers of female doctoral students and academics have increased over the last few decades, with some national higher education systems now registering the feminisation of doctoral cohorts (Gardner, 2008), gender imbalance persists in higher ranks in academia.

Some have argued that disadvantage and prejudice in the academy often take subtle, even hidden forms, and these forms apply specifically to women. For example, Johnson, Lee \& Green (2000) suggest that the very objective of graduate studies - the production of an autonomous scholar signified through a thesis with a solo author - already contains a strongly gendered message because it assumes the end product is a male, emotion-free, rational subject. Previous research has suggested that the privileging of white, single males in the operation of doctoral programs disadvantages those who are other, such as women and people of colour. Gardner (2008) showed that socialization during doctoral studies was more difficult for women, students of colour, parttime students, students with families and older students. Dever (2008) found that women were more likely to complete research programs on their own, without the benefits of working in a team. Other researchers, specifically Romero \& Margolis (1998), Russo\& Vaz (2001), Rodriguez (2006) and Ferreira (2003), Xu (2008), Alpay, Hari, Kambouri \& Ahearn, (2010) have used the concept of hidden curriculum, to explain how unwritten and unspoken expectations and values tend to be applied differently depending on students' gender, race and class.

To complicate this picture, because of the nature of their work, doctoral students are often treated as temporary colleagues. Their positioning as members of a (largely transitory) research 
workplace will affect the way we understand their experience as being affected by factors other than purely academic ones (Pearson, 1999, Pearson, Cumming, Evans, Macauley \& Ryland, 2011). Sweitzer (2009) and Pilbeam \& Denyer (2009) used social network theory to study doctoral student networks and concluded that students who faced barriers to participation, such as lack of physical proximity and caring duties, may be disadvantaged in the acquisition of vital tacit knowledge needed to negotiate the academic environment. Van Emmerik (2006) found that women used networks more for soft social capital, getting support but not getting access to resources, collaborations and promotion. Hopwood \& Paulson (2011) cite examples of female students resisting the advances of male supervisors or feeling out of place in a predominantly male (scientific) community, and lapsing into domestic roles (making tea and coffee) while on group field-work, to support an argument that gender is registered in everyday workplace practices.

However, in their study of female students' perception of their supervisors, Brown \& Watson (2010) showed that not all research participants indicated dissatisfaction with supervisors, although all supervisors were male. We should therefore approach the idea that male supervisors are always problematic for female students with caution. In fact, there are no conclusive data or consensus on whether female and male students have different experiences in working with supervisors. A number of studies suggest that male supervisors are not always as understanding of female student issues (Erickson, 2012, Haake, 2008) and tend to favour male students in terms of access to resources and additional employment opportunities (Katila \& Merlianen, 2010). Kantola (2008) studied the experience of being supervised by men for both male and female students. This research showed that there was evidence that some women were marginalized during the supervision process, for example, not offered teaching positions and / or their research topics being subjected to more critical scrutiny than those of men. Women in Kantola's study reported feeling that they do not belong to the department (in this case in political science) and were 
questioning their disciplinary identity. At the same time, Kantola's data also show that having a female supervisor does not automatically resolve problems of gender (2008).

The gender composition of the department in which candidates are located is a key factor in how gender is experienced as either a disadvantage or an advantage. Research conducted by UlkuSteiner et al. (2000) showed that satisfaction of students (both females and males) did not depend on the gender of their supervisor but did depend on the gender balance in the faculty as a whole. The study concluded that female students experience less support and lower self-esteem in maledominated departments, regardless of the gender of their supervisor. Research by Kurtz-Costers et al. (2006), Fried and MacLeave (2009), Haake (2008) supported the findings of Ulku-Steriner et al. about the importance of gender composition of the department rather that the gender of the supervisor. Haake (2008) showed that male-dominated, female-dominated and gender-balanced departments communicated different sets of values to their doctoral students. Ferreira (2003) also attributes attrition rates to the gender composition of the department. The study compared departments of chemistry and biology and concluded that attrition rates are higher among women than among men. However, it was lower in biology than in chemistry. The authors suggest that in the department with no female academics, female students were not able to modify the masculinised culture of the laboratory (p.984) and that a 'critical mass' of women among academic staff and students was needed to change the situation. However, the proportion of female academics to males on its own does not necessarily address these issues. Other research suggests that senior female academics assume the dominant faculty cultural norms and are not seen by female students as desirable role models (Alpay, Kambouri \& Ahearn, 2010, Kurtz-Costes, Andrews, Helmke \&Ülkü, 2006, Wall, 2008).

Situating the progress reporting instrument, as a managerial tool, within this complex milieu, and determining its effects, is therefore extremely difficult. Martin (2003) points out that it is 
important to ask whether academic practices are gendered as well as asking how such academic and organisational practices are gendered and suggests that it is a mistake to view gendered practices as fixed. Martin (2003) concluded it was more useful to talk about different masculinities and femininities, rather than gender as an expression of physical attributes. Gender is constructed and communicated on an everyday basis through organizational structure, symbols, and gendered labour division (Wall 2008, Katila and Merliainen, 1999). Following Butler (1999) we understand gender identity as a form of performance. People 'do gender' in organizations through discursive practices that tend to be reproduced over time and across locations. Every organization produces demands for certain kinds of performativities: specific types of masculinities and femininities. In other words, disadvantage may not always be a problem experienced exclusively by women. Men who do not readily behave in accepted masculine ways may find themselves disadvantaged as well. The work of Sallee (2011), who investigated male student experiences in an engineering department, showed that a particular type of masculinity was demanded from students. Some male students experienced degrees of discomfort trying to adjust to the accepted mode of masculinity required in this context. Additionally, we cannot assume that masculinities will always be privileged over femininities in all organisational settings.

\section{Research Design}

This study was conducted in a large Australian, middle-band, metropolitan university in 2010. Preliminary analysis of the old paper-based progress reporting system revealed some concerning anomalies, in particular that significant numbers of candidates had never had their progress reported as unsatisfactory, despite being past their mandated submission date. A research project, interviewing a range of stakeholders, was undertaken to inform both policy and administrative processes going forward, for which approval from the university's ethics committee was obtained. Supervisors and administrators were interviewed as part of the broader project and overall 
findings were reported in a previous paper (Mewburn, Tokareva, Barnacle, Sinclair \& Cuthbert, 2013), but these responses from supervisors and administrators do not form part of the analysis in this paper as the focus in on research student experience.

In all, twenty students were interviewed. Twelve in humanities, business or design disciplines and eight in the laboratory-based sciences/technologies or nursing. We included candidates who had at least two years' experience of candidature from those who responded to our call for participants (to ensure that participants had some prior knowledge of the system). Fifteen students took part in the three focus groups and five additional students were interviewed separately. We interviewed 8 men and 12 women and all were given pseudonyms (which reflected their original gender) for reporting purposes. We noticed that the call for participation tended to attract students who had strongly positive or strongly negative views and experiences with the progress reporting system - more on the significance of this is included in the discussion below. We were not concerned with getting feedback on the design of the form itself as it varied so much across the institution (we counted 26 different forms in our initial review of the paper system). We were interested in how the students perceived the process, especially its usefulness to them in the conduct of their research.

Each focus group and interview proceeded with a set of general questions about the participants' understanding of and approaches to the progress report process. The questions were designed to elicit narratives and reflection from the participants and draw out individual experiences of progress reporting. We did not ask students any questions which specifically referred to gender as an analytical category. All interviews were audio-taped and transcribed for later analysis. Analysis was based on techniques derived from grounded theory (Strauss \& Corbin, 1998; Boeije, 2002). Interviews were transcribed and subjected to a theme analysis by two researchers and an 
additional coder where possible. Pseudonyms are used in the quotations that appear below. Analysis was performed using Nvivo software, informed by a series of questions, specifically:

- Are there gender differences in the way men and women understand the purpose of the progress report and its effects?

- Do men and women report different experiences of and tactics for dealing with and working around official processes?

- How do men and women talk about working with their supervisor(s)? Were different working styles reported and were these gendered?

\section{How do men and women understand the purpose and effects of progress reporting?}

A surprising number of our participants were confused about the purpose of the progress report and how to complete them. In the absence of a clear narrative from the institution or their supervisors, our participants formed theories from a number of sources, including other students, even students at other institutions. In our previous paper (Mewburn, Tokareva, Barnacle, Sinclair \& Cuthbert, 2013) we discussed the tendency for students to theorise about the purpose of the report and who was reading it, and perform themselves in writing for this imagined audience, even if this audience was a void or some kind of 'silent witness'. In our analysis for this paper we were interested in how the men and women imagined an audience for the progress report differently. Petersen (2011) points out that the process of research supervision involves a process of subjectification (which we might call 'becoming supervisor') which produces certain kinds of 'academicity'. Similarly we see in our participants' accounts a process of 'becoming student', but, we argue, the academicity is experienced in gender specific ways.

On the whole women seemed more conscious of the audience - and of being watched and of being judged by it - than men. They also reported a wider variety of responses to this imagined audience - and a more conscious performance for it. Helen, an international student studying 
education, worried about how she might appear to unknown progress report reader 'I feel strange and I don't know my expression is appropriate or not and anything the school will expect me to write down'. Helen's progress reporting self is tentative and uncertain; wishing to do the 'right thing', but not quite knowing how to do so. Similarly, Martha, a science student, reported being worried about not knowing what was 'normal' and what the 'bench-mark was' for the content of her report. By contrast, Anna, a design student, told us her ideas about the progress report audience had changed after putting in a report which highlighted deficiencies in her supervision arrangements. Anna claimed she now thought of the progress report as 'almost ... an instrument for the school to kind of say "Well, you know, this is the way we can protect ourselves"'. For Anna the audience of the report revealed itself to her as self-interested and prepared to put its interests above her own; she explained how this induced from her a performance of 'student' that was more assertive. Her refusal to take the subject position of 'disciplined student' nearly resulted in her not being a student at all. Fighting fire with fire Anna read the university policy handbook and insisted on meetings to hold her supervisors to account for what she saw as departures from stated university policy. After holding the school to account for lack of adherence to policy, Anna's supervisors and administrative staff started a process to manage her out, which, lthough it was ultimately unsuccessful, was a source of considerable stress and damaged her relationships with both staff and other students.

Megan, a research candidate in the humanities, echoed Anna's view describing the progress report as 'a big risk management strategy' which is 'really just helping them', but she did not talk about needing to be more assertive in response. Megan seemed wary of the power of the bureaucratic machinery but took no action because her troubles never escalated into open conflict as Anna's did. By contrast, one of our women participants, Maggie, had a very different view of bureaucracy. Maggie described the progress report as '... just a form that I rarely think about. It is a list of what I have done in that six months and what I plan to do'. Maggie's matter-of-fact view of the 
bureaucracy may be a consequence of her employment in research administration and responsibilities for processing the same paperwork for other students. In contrast to Anna and Megan, Maggie experienced much less identity conflict and tension through her candidature. Maggie assumed two subject positions within the university, 'administrator' and 'student'and the first of these conferred on her 'insider knowledge' from which to analyse her own approach to the business of reporting.

Some women seemed to imagine the audience as largely absent, but likely to materialise at any moment, sometimes to do harm. Katrina, a student in the sciences wondered whether anyone was actually reading the reports but still claimed she self-moderated her reports because supervisor trouble was a 'touchy subject' that should be avoided:

[P]eople are still going to be afraid of whether, "oh are they going to read this thing? Is something going to happen? Am I going to be affected by this thing?" so they will always behaving with this fear of whether the supervisor's going to find out about it

We noticed that men talked about the imagined audience less than women and there was less diversity in the way they spoke about it. Without exception, men seemed to assume, like Maggie, that the progress report was part of a depersonalised 'risk management' apparatus of the university bureaucracy. This is consistent with the findings of Holligan, Wilson, \& Humes (2011) that male academics tended to talk about research culture in organisational terms, such as 'systems and outputs'. In our male participants' statements, the progress report was often figured as a tool or instrument for review and quality control. In line with this 'managerial' conception of the progress report, men appeared to figure the audience for the progress report as a fair and impartial arbiter, seeking facts and information. Unlike the majority of women, men seemed to 
assume that such 'nuggets' would be used to help resolve disputes or work out how a problem had occurred. This response from Dan, an international student in the sciences, was fairly typical of the male responses in our sample:

I actually don't know where it [the progress report] goes. I sort of know that it gets filed and my impression of the whole affair is that if someone had to look up a formal record of what happened in my progress, then they would go and look for it... if for whatever reason I was on the line and someone had to review my case, then they could look at these things and then make some reasonable judgement.

Similarly, Barry, a local student in the Business school commented:

I'm not totally sure what happens after that [the submission of the progress report]. I assume if I needed a copy of an old progress report I could contact that admin person and they'd be able to dig one up for me.

Our data may have bias in that none of the male students we interviewed had experienced major problems with their candidature. Our recruitment process was by email and asked for students with some experience of progress reporting. We noticed that our study tended to attract people who had strong views on progress reporting, but in men this seemed to manifest as views about business process, rather than about fairness and equity. In addition, men expressed fewer concerns about whether what they wrote on their progress report would affect their future relationships and wellbeing. For instance, while men seemed to assume that hearing nothing about the progress report meant business as usual; most women expressed annoyance or worry. For instance Cally, an international student in the humanities told us: '... I don't know where the report actually goes; I don't know who sees it; I don't know who it goes to and will the person actually read it? What happens to the report?' She then expressed concern about the fact that reports might be seen by people who are not supposed to see them. Others, like Katrina, an 
international science student, wondered if the audience was even paying attention: 'I'm not too sure whether they are actually reading all these problems we are encountering'.

The different imagining of the progress report audience spoken of by participants was strongly gendered. We are not in a position to determine whether these differences have any tangible effects on the progress of candidature, but they do suggest that women expend significantly more energy, either on crafting their progress report or worrying about it, than men do. Women seemed to feel they are being made subject, or subjugated in ways that men do not report.

The women in our sample seem to experience the policing of themselves as doctoral students more intensely than their male peers. As a result their accounts are generally more emotionally amplified -- anxious, submissive, aggressive, while the male accounts are disengaged, even nonchalant. This could be interpreted as a more politicised understanding of doctoral life, although our one 'anomalous' women, Maggie, with her insider knowledge of the system, displayed more of a 'masculinist' sensibility towards the progress reporting process. This may reflect a marginalised subject position; certainly women seemed more uncertain of the place they occupy in the academy. It is concerning that the majority of women in our study felt more vulnerable to the effects of power than men, and their concerns over the possibility for power to be used against them was not confined to the supervisor relationship, but generalised to the administrative apparatus of the institution - a domain that is often figured as gender neutral. Earlier we noted that disadvantage and prejudice in the academy often take subtle, even hidden forms. These accounts from our participants call into question whether the managerial apparatus of the university does promote transparent, fair and equitable outcomes, or whether it merely throws a veil over the continuing operation of gender discrimination inside the academy. 
Paper work was seen by most of our participants as a way to solve resourcing issues and make requests for materials, but the progress report, as a formal 'channel' was not used to solve all problems students encounter during candidature. In our previous work on progress reporting (Mewburn, Tokareva, Barnacle \& Sinclair 2012) we noted the reluctance of all students to use these formal reporting mechanisms to address 'people problems'. The formal channels were seen to be too blunt to do the necessary emotional/interpersonal work -- soothing hurt feelings and easing interpersonal tensions that arose between supervisors and students. Students, supervisors and administrators all searched for ways to solve problems that avoided official paperwork, with varying degrees of success. In our previous paper we called this practice 'working the back channels'. We saw the back channel as a proxy for how much agency each student felt they had in the community in which they were located.

Men in our sample talked about back channels far more than women did. Generally the men we talked to seemed to be more aware of the existence of back channels to help get things done without the need to record requests or problems on the progress report. Dan, a computer science student was particularly adept at this back channel work:

... if I have an issue with my computer or something, or with the library system, I'm not going to wait six months to raise this thing. There seems to be a lot of avenues where you can raise it. I mean, in the school I know there's one person that sort of deals - that's all I know about them; is that if you have an issue that I can't raise with your supervisor, you can go there.

When pressed about how he knew of this Dan was unsure if he had picked up the information in an email or in conversation. Similarly Greg, a social science student, told us that: 
my ability to work in this type of environment is something I'm very comfortable with... I'm very good at ensuring my own needs are met, so if there is something that needs doing then I just find out how to do it and make it happen.

Greg gave us an example of joining a discussion group at another local university as a solution to the lack of "intellectual ferment" within his school.

Other men seemed to be aware of back channels, but did not report having to activate them. In contrast to the stories reported by many of the women in our study, supervisors of men seemed willing to step in and play the role of problem solver. In these cases the supervisor became the best kind of 'back channel' to solve problems that obviated the need to resort to any kind of paperwork. Olaf, a student in Art, admitted to being confused by formal administrative processes of the university and leaning heavily on his supervisor, but this help extended into 'non-academic' activities too: '... I told him that I was kind of getting bored working by myself there in my studio and kind of would like to experience part time job working in a gallery or that sort of thing.' Olaf reported that his supervisor had undertaken to look into procuring this work. Similarly Stewart, a design student, reported:

... maybe I am fortunate enough that I don't have any issues of that sort ... [if I have needed] extra help and additional resources, my supervisor has been able to dig these out from wherever it is possible.

Consistent with the literature on networking (Benschop, 2009, Van Emmerik 2006, Gershik et al. 2006), we found that most women while seemingly aware that there were back channels did not actively report using them to get extra resources. Unlike the men in the instances above, women did not report supervisors 'pulling strings' to find extra resources or solve problems. Katrina, a science student, had experienced many difficulties in getting money to purchase materials and pay for expenses in collecting data. She claimed that she was aware there were 'a lot of politics in the 
department' from the conversations she overheard in the tea room, but did not seem to know how to use these politics to her advantage. After her requests for extra funding were persistently ignored by her supervisor, she reported: '[I was] left to manage the situation on my own or seek help from peers or something like that. So I had that problem, and I didn't know who to actually tell these problems to'. After some time Katrina started trying to use the progress report to escalate the problems, but did not have any luck until a new Dean facilitated a meeting on the phone between the group of students and Katrina's supervisor. After the phone call ended the Dean 'switched off the phone and asked us all individually what we thought of this situation'. Katrina reported that it was only after this meeting that she felt she was listened to.

Other women reported being aware there must be back channels, but the workings of them were invisible or inaccessible for some reason. As Cally, a social science student remarked: 'If I had a problem with my supervisor I wouldn't know what to do... in every organisation there are rules; in every organisation there are personal relationships that tend to stretch the rules... here, I have just seen all kinds of bending of the rules'. Cally cited her background in another country which she claimed was more attentive to probity as the reason why she could not bring herself to bend rules in the same way. Zelda, a student in business, needed to undertake software training which was not offered within the university. Her supervisor did not seem to be any help as 'she [is] my supervisor on paper but [I have to] go off and find other people to help me'. Zelda reported that although her supervisor had found some 'names' she hadn't 'actually come up with the goods yet'.

The back channel dealings participants described seemed to be strongly gendered - even more so than the reactions to the imaginary audience reported in the last section. The masculinities produced here seemed to involve a stronger sense of agency: the ability to bring resources to bear to solve problems outside of normal processes. The women's accounts also display agency - but it 
is of a qualitatively different sort from men's. While women reported striving to find alternative ways of solving problems, they seemed to find the workings of back channels more opaque and difficult to access. Those women who were aware of alternative routes to getting what they needed tended not to use them because they wanted to play by the rules or did not think that the outcome would be worth the effort. Both these findings are, again, consistent with the literature on networking (Benschop, 2009, Van Emmerik 2006, Gersick, Dutton \& Bartunek, 2006). It is significant that the women we talked to did not seem to use their supervisor to solve problems in the same way that men did. There are two possible reasons for this: either the women did not want, for some reason, to ask their supervisors to solve these problems; or the supervisors themselves did not suggest, or seek to activate, back channels for this purpose.

\section{Working with supervisor(s)}

When asked to explain how they worked with their supervisor to produce progress reports, participants disclosed much about what we might call their preferred working 'styles' and how these conflicted (or not) with the working style of their supervisor. Given our sample size and research design we are not in a position definitively to add to the debate on how male and female supervisors do their work. However the remarks about working together did elicit some evidence of gendered performances in the supervisory space. While differences in disciplinary cultures are key factors in these relationships, some gender-based differences appear to transcend these disciplinary differences.

On the whole men seemed to assume a functioning relationship with a supervisor as a normal state of affairs, which is in contrast to the assumptions and experiences of many of our female participants. As Brendan, a science student told us: '... you have to have a very good relationship with your supervisor to finish your PhD in a good way'. All of the men in our sample reported 
having good academic working relationships with their supervisors, where 'good' is understood as an arrangement of work and responsibility that suits both parties.

In some cases the arrangement was close, with the supervisor providing ample encouragement and direction. Olaf, an international student working in Art, told us how his supervisor acted like a 'recorder' of the progress report, talking with him about the progress and then going away and writing up the report for Olaf's later approval. This discussion seemed to be wide ranging, as Olaf stated:

We together try to discuss about my project and what I have to do in the next six months... it's kind of good experience, working together with my supervisor to complete that form... [the discussion started with] general things like what I have been doing... my family, my work and my studio...

In contrast to this kind of inter-dependency, other men reported a much more distant, yet comfortably collegial relationship of equals. As Greg, a domestic student in the social science school reported:

I think you could take away from what I already said the impression that my supervision has been very unsatisfactory. But the truth of the matter is that I would describe it as benign neglect, which actually suited me immensely. So it meant that my personal performance wasn't being closely monitored and it left me with the opportunity to follow my nose... the supervision that I've received has been exactly what I needed only because it was absent.

This experience was echoed in this statement from Neville, a student in the computer sciences who said: '... My relationship with my supervisor is quite loose, in that he gives me room to explore where I want'. 
The progress report itself became a source of strain between Andrew, another science student, and his supervisor. Andrew reported a close relationship with his supervisor that was '... very good. He's the nicest person here' and went on to describe the opportunity the progress report provides to have a longer conversation: 'my supervisor calls me into his office and we have a two hour chat about my PhD. We reflect on what we have done and what we have not'. This relationship became strained due to problems with the supervisor's tardiness over the progress report, which caused Andrew to grow anxious about the status of his student visa. While Andrew reported being very stressed and upset about this incident, he went to pains to tell us that he did not place the blame for this on his supervisor, but rather on the (female) administrators of research in his department.

Being in a supervision relationship with a supervisor of the same gender appeared to affect the way students talked about their working relationship with their supervisor. In our data women in all disciplines tended to report working well with women; likewise men tended to report working well with men. This pattern was marked when students talked about the effectiveness of their supervisor. For instance Agatha, a communication student, told us how her supervisor would remind her that the progress report needed doing and they would collaborate to produce an account together.

She's my supervisor therefore we actually work so closely we know what is really going on. Most of the times we don't really need to meet to ask questions. We're already in the process of commenting to each other and when a problem arises we communicate it to each other.

Nonetheless, Agatha still seemed very sensitive to the power differential in the relationship: 'I know my supervisor has the power. If she writes one unsatisfactory report ... it will have direct consequences affecting me'. Venetia, a science student, thought her supervisor was '... very supportive/good; she's very helpful', citing an instance where her supervisor called Venetia while 
on holidays because her report was overdue and helped her revise it over the phone and via email. Similarly, Margaret, a student in business, reported a close relationship with her female supervisor, even though Margaret was a part time student and entitled to less time with her supervisor under university policy:

Even though I am only part time I meet with my supervisor on a weekly basis, so our meetings could be "Let's have a coffee. Let's talk about what is happening in my week", or it could be a PhD meeting.

Megan had a high profile supervisor who did a lot of travel and found it difficult to organise the progress reports as a consequence. Despite their time apart, Megan reported that she had negotiated a solution with her supervisor whereby the supervisor would keep an eye on the deadlines and Megan wrote the majority of the report. Megan reported this arrangement as an example of their 'pretty good working relationship'.

Agatha, Megan and Margaret's experiences can be contrasted with Katrina, another female science student who was working on an industry project with a large team of students and a male group leader. Katrina's report is marked by remarks about neglect and forgetfulness on the part of her male supervisor such as this:

[S]o the day before [...] because he knows he had to get it in by the due date, he would sit down and actually spend the time to have a look at each of our progress reports. Probably about five minutes for each person, and he will quickly send it back to us.

Later on Katrina tells us about raising a problem over funds in the progress report itself, which was never followed up because '... probably he forgot about that too'. Katrina's supervisor was travelling a lot and did not seem to be in the lab to see the working conditions of his students. Complaining about this aspect of her experience Katrina remarks: '... he doesn't seem to 
understand that some people might be able to write and do their work as they go, but when we're doing 18 hours of experimental work, hardly any sleep...'.

This female to male story of neglect could be contrasted with the accounts of 'benign neglect' from our male-to-male relationships mentioned above. Greg, a student in social science, reported what might be construed as neglectful behaviour from his male supervisor actually provided him with what he needed to get on with his research. . He emphasised that what seemed like neglect in this relationship suited him "immensely". What others might frame as neglect, Greg framed as a form of trust. This is echoed by Neville, a science student, who describes his relationship with his supervisor as 'loose'; they meet only every six months, but Neville presents this as desirable because his supervisor gave him freedom to explore what he wanted. Stories of feeling neglected in the context of male-to-male relationships were rare in our sample. It's possible that the women in our sample were more neglected than our male students, or experience what to men is 'normal' supervisor behaviour as neglect. It is worth noting that perception of neglect, benign or otherwise, indicates that some of the supervisors of our participants were not performing their duties adequately.

Some female students studying with male supervisors reported an actively hostile relationship rather than a passively dismissive one. Anna, a design student, had two supervisors, one male and one female. She reported outright hostile interactions with her supervisors over the content of her progress report. For Anna the progress report had become a kind of 'battle ground' where she struggled to assert her voice: "I had a meeting but it was a meeting, kind of going into every question and telling me -- trying to convince me, "this is the way we are doing it". There was no discussion'.

Two accounts of female students depart from the pattern of female candidates having difficulties 
with male supervisors. Zelda, a student in business, changed her supervisor several times and reported very strenuous relationships with her first supervisor (female). She mentioned that she had a 'problem' with her supervisor and therefore doing progress reports was a very 'confronting thing'. Cally, a social science student with a male supervisor, on the contrary, emphasised that she experienced no issues with her supervisor, describing their relationships as 'straightforward':

$[H]$ e's aware of my situation but I don't have any accidents; haven't had any additional unexpected situations. Actually, what he has done, it's just been very straightforward. When I met him, it's "one chapter next time, one more chapter, one more chapter" and that's it. So it's been quite clear.

Of the female students reporting to male supervisors we found instances of mixed experiences. Some, like Helen, an education student, reported what seemed like highly directive interactions around the management of progress reports:

Actually, I don't know anything. I didn't know anything about it when I first been here or I need to write something about that. It was a very scared and very anxious time, and he help me a lot. My first one, I think he did 50 per cent for me, I think.

This directive relationship seemed to suit Helen however, and she told us how, gradually, she was able to take more of an active role and draft the whole report herself, but still very much under the guidance of her supervisor. The passivity of Helen is echoed by Valerie, a science student, in her description of how her supervisor goes about doing the progress report: '... like, we are not sure - we are always following what our supervisor is telling us and we trust him'.

Similarly directive relationships were reported by Olaf, a student in Fine Art, whose supervisor 'takes all that information and he complete the progress report himself'. Unlike Helen however, Olaf reports that his supervisor gives him the opportunity to check over the content of his report. Stewart, a student in manufacturing reports a similar process where the progress report is passed 
back and forth in a process which was 'not exactly a negotiation' because the greater knowledge of the supervisor is viewed by him as power which Stewart was careful to respect.

Notably, while many of our female students had male supervisors, our sample delivered only a small number of examples of female supervisors supervising male students. This is a phenomenon that may require further investigation. In the two cases in our sample, the relationship seemed to be easy going, as Dan, a scientist noted: '... we meet every week, so she's completely aware about everything I am doing inside out, and my life and everything else... the progress report took five minutes'.

The variation in reported experiences of students of each gender being supervised in same-sex and different sex relationships calls for further research into gender-based dynamics and perceptions in the supervisory space. It is clear, even from this small sample, that gender makes a difference to both the dynamic and the way it is framed. For, example, we found that what might appear to be negligent supervision to many female candidates tends to be 'framed' as trust and freedom to explore by male candidates.

\section{Why do these gender differences exist?}

The differences in how male and female graduate students understand and talk about the process of progress reporting troubles the assumption that managerial tools like progress reporting forms necessarily bring clarity and equity to the process of doctoral education. It is difficult to make one strong claim as to why the differences we noted exist. There were no reports of outright sexism, yet the potential for systematic disadvantage on the basis of gender in administrative processes is real - and disturbing. 
One could argue that these differences exist because female and male students bring different psycho-social orientations to the way they view the university as an organisation. There is some evidence for this theory in the way men and women tended to create different 'imagined audiences' for their progress report. The women in our study tended to style this audience as being in a position of power that can potentially do harm. The men tended to talk about this audience as more fair, rational and administrative (neutral) in nature. However we must be wary of sweeping generalisations, which neglect to pay attention to the environment in which people are located and the power relations which are constantly produced in organisational structures.

It is more likely that these different framings of the administration process might stem from what Valian (1999) calls 'gender schemas', non-conscious assumptions and expectations that women and men both tend to apply to others. Schemas differ from stereotypes, Valian argues, as they are a by-product of the human tendency to theorise and are simultaneously communal and idiosyncratic. Valian claims these schemas deeply affect how we view behaviour in the workforce, of ourselves as well as of others because they '... influence what information we pay attention to, our interpretations of that information, and the predictions we make about ourselves and others' (Valian, 1999).

Valian's explanatory framework can be applied to our data to useful effect. For example, the finding that male students demonstrated more awareness than females of the "back channels", and reported more ease in using them made us, as we were interviewing, feel frustrated. It seemed to us that women were suffering unnecessary disadvantage because when they asked for help they did not always receive it at least to the extent that they wanted or needed it. Many seemed to assume that it was not possible to progress a complaint or request outside of 'normal' channels. On the occasion where a woman knew this was possible, the woman seemed to assume 
that the answer would be no. As a result we wonder whether women lose faith in these processes and just not ask for what they need or want in the first place (Babcock and Laschever, 2008).

Would women be treated like men if they acted more like them? If Valian is correct, requests from women which 'bend' the organisational rules may well be viewed differently than the same requests from men. Valian notes that assertive behaviour from men tends to be more positively framed by the recipient than assertive behaviour from women (this finding is supported in work by Bowles, Riley, Babcock and Lai, 2007). Women can be expected to take on more traditional gender roles which include the possibility of taking up a more subservient, even victimised, position within the organisational hierarchy . Butler (1999) argues that women who do not act in 'gender appropriate' ways are often ostracised. We could see this tendency in Anna's story most clearly; her self advocacy had the effect of mobilising the resources of the department to silence her. Given the large attrition rates from doctoral degrees, as we highlighted at the beginning of this paper, If gender manifs as an issue of concern in administrative processes intended to facilitate and monitor progress, we need to seek better understandings of how gender identities are produced by them.

Our findings have implications for the way we manage research degrees within institutions, but also more broadly in terms of student interaction and management of paper work at all levels within the academy. Paperwork is seen as an instrument to smooth out differences and inequities and bring transparency and accountability to academic practices, but these accounts, particularly stories about use of 'back channels', challenge the assumption that all paperwork practices are neutral. The variety of gendered practices around progress reporting, and the patterns we have highlighted, demonstrate that supposedly 'gender neutral' institutional processes may have gender-differentiated meanings and impact on the students they are designed to support. 


\section{Conclusion}

Our data show that banal administrative processes can be a window onto the complexities of the doctoral experience and the possibilities of marginalisation and discrimination within seemingly routine institutional practices. Given the unevenly weighted gender composition of some disciplines, in particular science and nursing, the ability to take up (or not) masculinised or femininised practices might carry with it advantages and disadvantages for doctoral students. With Haake (2008), we argue that the discussion of gender equality should be broadened to encompass the changing gender (and other) demographic composition of higher education. While the situation faced by women and minorities in male-dominated fields require ongoing work, more complex situations demand our attention as researchers. We need to account for femaledominated fields, for example, and for the experiences of a range of different men relative to the normative masculinity assumed in some disciplinary settings. As student and staff demographics shift, so the issue of gender balance and equality needs to be constantly revisited.

Our observation that women are more aware of, and attentive to the political aspects of their candidature should give us pause to think about how female students perceive their place (or not) in the academy and the role that supervisors and administrators might play in the development of these perceptions. It is clear that many of our female participants reported that they did not experience full membership of the academy, even if they were not marginalised. Supervisors and administrators should take more care when briefing women and men on the role and purpose of the progress report and other administrative processes, and take women seriously when they report issues with these processes that appear on the surface to be neutral and fair.

There are limitations to our findings. Our sample size of 20 students within one institution, and the lack of any systematic research on the topic of administrative paperwork in doctoral candidature, 
make it difficult to know how wide spread the gendered practices we report here are within Australian universities - or within other universities around the world which use similar systems to manage candidature. . However while our sample is small, our data are rich and this analysis indicates that gender is an important factor in working relationships between students, supervisors and the administrative structures of the university. In fact, our research calls into question the ostensible reason for using progress reporting to manage doctoral candidature at all. Given the inconsistencies in how our candidates experienced and perceived progress reporting, the claim that such technology produces equity and fairness looks weak. If it is desirable for candidature to be monitored and 'policed', other methods may have to be sought out and tested. More research is required to investigate whether these practices affect the success, or otherwise, of candidature.

\section{Acknowledgements}

The authors would like to thank the peer reviewers, particularly the peer reviewer who kindly sent us a version with very specific comments. We appreciate the diligent, careful way this reviewer entered into the work and the constructive feedback that s/he offered.

\section{References}

Asmar, C. (1999). Is there a gendered agenda in academia? The research experience of female and male PhD graduates in Australian universities. Higher Education, 38(3), 255-273.

Alpay, E., Hari A., Kambouri M., \& Ahearn A. L.. (2010). Gender issues in the university research environment.'European Journal of Engineering Education, 35(2), 135-145.

Babcock, L., \& Laschever, S. (2008). Women don't ask: Negotiation and the gender divide. New Jersey, Princeton University Press.

Benschop, Y. (2009). The Micro-politics of Gendering in Networking. Gender, Work \& Organization 16(2), 217-237.

Boeije, H. (2002) A purposeful approach to the constant comparative method in the analysis of qualitative interviews.'Quality \& quantity, 36 (4), 391-409. 
Bowles, H. R., Babcock, L \& Lai, L. (2007). 'Social incentives for gender differences in the propensity to initiate negotiations: Sometimes it does hurt to ask. Organizational Behavior and Human Decision Processes, 103(1), 84-103.

Brown, L, and Watson, $\mathrm{P}$ (2010). 'Understanding the experiences of female doctoral students.' Journal of Further and Higher Education, 34(3), 385-404.

Butler, J. (1999). Gender Trouble: Feminism and the Subversion of Identity, Routledge, New York.

Bell-Ellison, Bethany, A., and Robert F. Dedrick (2008). 'What do doctoral students value in their ideal mentor?. Research in Higher Education, 49(6), 555-567.

Dever, M (2008). Gender differences in early post-PhD employment in Australian Universities: The influence of PhD experience on women's academic careers. Brisbane, The University of Queensland Social Research Centre (UQSRC).

Edwards, D., Radloff, A., \& Coates, H. (2009). Supply, demand and characteristics of the higher degree by research population in Australia. Camberwell, Australian Council for Educational Research.

Elg, U and Jonnergård, J. (2003). The inclusion of female PhD students in academia: A case study of a Swedish university department. Gender, Work \& Organization, 10(2), 154-174.

Van Emmerik, I. J. (2006). Gender differences in the creation of different types of social capital: A multilevel study. Social networks, 28(1), 24-37.

Erickson, S. K. (2012). Women Ph. D. Students in Engineering and a Nuanced Terrain: Avoiding and Revealing Gender. The Review of Higher Education, 35(3), 355-374.

Ferreira, M. (2003). Gender issues related to graduate student attrition in two science departments. International Journal of Science Education, 25(8), 969-989.

Fried, T, and MacCleave, A (2009). Influence of Role Models and Mentors on Female Graduate Students' Choice of Science as a Career. Alberta Journal of Educational Research, 55(4), 482-496.

Gardner, S. K. (2008). Fitting the mold of graduate school: A qualitative study of socialization in doctoral education. Innovative Higher Education, 33(2), 125-138.

Gersick, C., Dutton, J., and Jean M. Bartunek (2000). Learning from academia: The importance of relationships in professional life.'Academy of Management Journal, 43.6 (2000): 1026-1044.

Golde, C. M. (2005). The Role of the Department and Discipline in Doctoral Student Attrition: Lessons from Four Departments. Journal of Higher Education, 76(6), 669-700.

Haake, U. (2011). Contradictory values in doctoral education: a study of gender composition in disciplines in Swedish academia. Higher Education, 62(1), 113-127.

Holligan, C., Wilson, M, and Walter Humes (2011). Research cultures in English and Scottish university education departments: an exploratory study of academic staff perceptions.'British Educational Research Journal, 37(4), 713-734. 
Johnson, L., Lee, A. and Bill Green (2000). The PhD and the autonomous self: gender, rationality and postgraduate pedagogy. Studies in Higher education, 25(2), 135-147.

Kantola, J. (2008) Why Do All the Women Disappear? Gendering Processes in a Political Science Department. Gender, Work \& Organization, 15(2), 202-225.

Katila, S and Meriläinen, S (2002). A serious researcher or just another nice girl? Doing gender in a male-dominated scientific community. Gender, Work \& Organization 6(3), 163-173.

Kurtz-Costes, B., Helmke, L.A. and Beril Ülku Steiner (2006). Gender and doctoral studies: The perceptions of Ph. D. students in an American university. Gender and Education 18(2), 137-155.

Lovitts, Barbara E. (2001). Leaving the ivory tower: The causes and consequences of departure from doctoral study. New Jersey, Rowman \& Littlefield Pub Incorporated.

Martin, P.Y (2006). Practising gender at work: further thoughts on reflexivity. Gender, Work \& Organization, 13(3), 254-276.

Mewburn, I, Tokoreva, E., Barnacle, R., Sinclair, J. and D. Cuthbert (2013). These are the things which shouldn't be raised in black and white: the culture of progress reporting in research education (forthcoming) Journal of Higher education and research development.

Pearson, M. (1999) The Changing Environment for Doctoral Education in Australia: implications for quality management, improvement and innovation. Higher Education Research \& Development, 18(3), 269-287. d

Pearson, M., Cumming, J., Evans, T., Macauley, P., \& Ryland, K. (2011). How shall we know them? Capturing the diversity of difference in Australian doctoral candidates and their experiences. Studies in Higher Education, 36(5)

Pilbeam, C, and Denyer, D. (2009) Lone scholar or community member? The role of student networks in doctoral education in a UK management school. Studies in Higher Education, 34(3), 301-318.

Margolis, E, and Romero, M (1998). The department is very male, very White, very old, and very conservative: The functioning of the hidden curriculum in graduate sociology departments. Harvard Educational Review, 68(1), 1-33.

Rodriguez, D. (2006) Un/masking Identity Healing Our Wounded Souls. Qualitative inquiry 12(6), 1067-1090.

Romero, M. (2000) Disciplining the Feminist Bodies of Knowledge: Are We Creating or Reproducing Academic Structure?. NWSA Journal, 12(2), 148-162.

Rose, G. L. (2005) Group Differences in Graduate Students' concepts of The Ideal Mentor. Research in Higher Education, 46(1), 53-80.

Felipe Russo, N. and Vaz, K (2001) Addressing diversity in the decade of behavior: Focus on women of color. Psychology of Women Quarterly, 25(4) 280-294. 
Sallee, M.W. (2011) Performing masculinity: Considering gender in doctoral student socialization.' The Journal of Higher Education, 82(2), 187-216.

Strathern, M. (ed.). 2000. Audit cultures: anthropological studies in accountability, ethics and the academy. London, Routledge.

Strauss, A and Corbin, J. (1994) Grounded theory methodology. In The SAGE Handbook of qualitative research, Lincoln, N.K. and Denzin, Y.S. (eds), 273-285.

Sweitzer, V. B. (2009). Towards a theory of doctoral student professional identity development: A developmental networks approach. The Journal of Higher Education, 80(1), 1-33.

Ülkü-Steiner, B, Kurtz-Costes, B. and C. Ryan Kinlaw. (2000). Doctoral student experiences in gender-balanced and male-dominated graduate programs. Journal of Educational Psychology, 92(2), 296-307.

Valian, V. (1999). Why so slow? The advancement of women, Cambridge, Massachusetts, MIT Press.

Wall, S. (2008) Of heads and hearts: Women in doctoral education at a Canadian university. Women's Studies International Forum. 31(3), $219-228$.

Xu, Y. J. (2008). Gender disparity in STEM disciplines: A study of faculty attrition and turnover intentions. Research in Higher Education, 49(7), 607-624. 